\title{
Evolutionary perspectives on economic policy
}

\author{
Marco Lehmann-Waffenschmidt ${ }^{1} \cdot$ Michael Peneder $^{2}$ D
}

Accepted: 18 November 2021 /Published online: 29 January 2022

(c) The Author(s), under exclusive licence to Springer-Verlag GmbH Germany, part of Springer Nature 2021

\begin{abstract}
Evolutionary processes are characterised by genuine uncertainty. Consequently, economic policy must take into account that environmental conditions and alternatives for action are often indeterminate. Scientifically sound concepts, methods and instruments are needed that take into account the partial openness of economic processes in real time. This editorial introduction provides a brief summary of the main findings of the individual articles in this special issue. Although each contribution can only highlight a specific problem, taken together they impressively demonstrate the relevance and urgency of developing a truly evolutionary perspective on economic policy.
\end{abstract}

Keywords Evolutionary change $\cdot$ Genuine uncertainty $\cdot$ Policy rationales $\cdot$ Agentbased models

JEL codes $\mathrm{A} 11 \cdot \mathrm{B} 25 \cdot \mathrm{B} 52 \cdot \mathrm{C} 63 \cdot \mathrm{E} 14$

Evolutionary perspectives on economic policy make it necessary to deal with processes that unfold into a more or less unknown future and thus are characterised by genuine uncertainty. As a consequence, economic policies which take account of genuine uncertainty, must go beyond the familiar notion that economic choices suffer from limited information about alternative courses of action, and must additionally consider that environmental conditions and alternative courses of action are in most cases indeterminate. Scientifically sound concepts, methods and instruments are needed that account at least for the partial openness of economic processes in real time.

Michael Peneder

michael.peneder@wifo.ac.at

Marco Lehmann-Waffenschmidt

marco.lehmann-waffenschmidt@tu-dresden.de

1 Fakultät Wirtschaftswissenschaften, Technische Universität Dresden, 01062 Dresden, Germany

2 Austrian Institute of Economic Research (WIFO), Arsenal Objekt 20, 1010 Vienna, Austria 
Besides the well-known differences in behavioural assumptions, cognitive processes and social coordination, the evolutionary perspective is distinct in various dimensions of economic theory. To begin with, Ulrich Witt (2022) emphasises its more comprehensive epistemological interest. This is because it not only asks how and why the economic system functions, but also strives for an understanding how systems and their components develop in a sequence of causal, or contingent, interactions within historically specific contexts and conditions. At the same time, he identifies a common interest among the evolutionary approaches in understanding the particular objects of research in the context of the economic change to which they are subject and which they also shape.

Such premises inevitably lead to a different approach to policy-making. Theoretical rationales are traditionally based on the dichotomy of arguments for or against government intervention. On the one hand, we find arguments for free markets and laissez-faire that focus on multiple causes and forms of "policy failure". On the other hand, proponents of state intervention either invoke the familiar justifications of "market failure" or alternatively refer to concepts such as "system failure" or "strategic failure". Peneder (2017) criticises this ubiquitous "rationality of failure", whether of markets, governments or systems, because it is rooted in a peculiar attitude of economists to accept hypothetically perfect states as normative benchmarks for individual and political action. However, in an open dynamic system with heterogeneous actors and preferences, a multitude of relevant parameters of performance and multiple local coordination equilibria, such optimal paths of development are de facto impossible to determine and therefore offer deceptive benchmarks for public intervention. Instead of the prevailing negative intervention logic, economic policy should be positively oriented towards the goals it actively wants to achieve. Concluding with a tentative typology of evolutionary economic policies, he classifies a variety of public interventions according to their specific target levels and systemic functions, while integrating them under the common objective of enhancing the system's ability to evolve in a socially desirable way.

But what difference does it make, whether we apply one or the other logic of intervention? Nelson (2009) highlights the more realistic approach to institutional complexity as one of the main advantages of evolutionary theorizing. Obviously, this is particularly important to the design and practice of economic policy. Accepting genuine uncertainty together with a strong dependency of the effectiveness of public interventions on the situational context renders the idea of optimized policy prescriptions untenable. Instead, the evolutionary approach emphasises the importance of policy experiments and the need to provide institutional space for processes of discovery (Metcalfe 1998; Cantner and Pyka 2001).

The individual contributions to this special issue on Evolutionary Perspectives of Economic Policy pursue different avenues to advance this agenda. Schmiel and Sander (2021) open this collection by addressing the market as a fundamental social technology for regulating economic exchange. In "What are markets? Selected Market Theories under Genuine Uncertainty Compared" they examine and compare three common market theories from a critical rationalist perspective, focusing on their ability to deal with genuine uncertainty. First, new institutional economics understands markets as a social arrangement that enables boundedly rational 
actors to maximise their utility through voluntary and therefore mutually beneficial exchange. Second, approaches that conceive of markets-as-institutional-arrangements consider optimisation to be an unrealistic idealisation of social processes, but emphasise the ability of markets to enable the reciprocal coordination of plans. Provided appropriate rules are in place, markets thus enable a potentially harmonious system of exchange. Third, the political-cultural approach views the market as an arena of social and political struggles whose harmonious coordination depends on a balanced distribution of power. The authors consider the first theory unrealistic and the second a special case of the third approach and conclude that political-cultural theories are the most realistic and general theory of the market. The important policy implication is that properties such as freedom of choice and mutual consideration of legitimate interests of other participants require a symmetrical distribution of power or at least an alignment of such objectives with the respective self-interests of powerful market participants. Clearly, these are important lessons for the design of a resilient market order that supports the overall ability of an economy to evolve in a socially desirable way.

Another fundamental premise of evolutionary perspectives on economic policy is the multi-level ontology of economic development, where the meso- and macrolevel of activities mean more than the mere statistical aggregation of the respective micro-units (Dopfer et al. 2004). Higher level ontologies shape the resource pools and selection environment for individual actors. Entry, exit, differential growth and learning processes drive structural change, which in turn leads to the emergence of different characteristics and empirical regularities than can be observed at the level of micro-units.

In the article "Levels of structural change: An analysis of China's development push 1998-2014", Heinrich et al. (2021) examine the correspondence of empirical regularities at the meso and micro levels for one of the most astonishing economic transformation processes we can currently observe. They combine sectoral data from the World Input-Output Database (WIOD) with extensive company data from the Chinese Industrial Enterprise Database (CIE DB) for the years 1998 to 2013. By looking at the so-called Fabricant's laws, they confirm a number of general statistical correlations between the growth of e.g. output, labour productivity, wages, capital and employment growth at the meso level of industrial sectors. However, they also find that many of them no longer hold when examined at the micro level of individual firms. For example, they find no significant correlation between labour productivity growth and value added growth. A likely evolutionary interpretation is that differences in average productivity, together with the reallocation of production towards firms with above-average productivity (through entry, exit and reallocation among incumbents), dominate the positive correlation of value-added growth and productivity at the sectoral level. An important policy implication is the need to create, shape and maintain open markets and promote industrial dynamism, as this drives the effective reallocation of output towards the more productive micro-units and thus overall labour productivity growth. At the end of their article, Heinrich et al. point to the relevance of industrial policy measures to support specific sectors and emphasise the importance of economic complexity and the relatedness of these sectors in product space. 
In their article "Capability Accumulation and Product Innovation: an AgentBased Perspective" Gräbner and Hornykewycz (2021) focus specifically on the latter point. After discussing various mechanisms of capability accumulation, such as own investment in R\&D, knowledge spillovers, worker experience, alliances and joint ventures, they develop an agent-based model with product innovations in order to shed light on the non-trivial interactions between micro and macro levels of economic activity. In short, the authors show that variations in the topological structure of an artificial product space, which represent differences in the relatedness of products in an economy, critically affect the innovation dynamics of the model. Examples of such differences are the centrality of products and whether the complexity of products is associated with their higher centrality or is randomly distributed. Both structural features are important because they influence the ease of accumulation of innovation capabilities and thus the diversification of individual firms. The authors thus demonstrate the degree and form of the relationship between products to be important factors for the design of effective industrial and innovation policy.

This is followed by an article with the self-explanatory title "Labour and environment in global value chains: An evolutionary policy study with a three-sector and two-region agent-based macroeconomic model" by Gerdes et al. (2022). Therein, the authors develop and explore a "testbed" for simulation experiments of economic policies, guided by the authors' concern to investigate the evolutionary political economy of unequal exchange. In the stylised model, global value chains are represented by the production and trade of natural resources extracted in the Global South, capital goods produced in the Global North and final goods for domestic consumption produced in both locations. The model depicts a fragmented international production system with unequal trading terms and climate change, which is ultimately rooted in the historical developments and interactions between the two regions. The desired policy mix is motivated by the institutional concept of a "civilised market" in which free enterprise and competition are reconciled with basic social goals and environmental imperatives. Available options include both command-and-control mechanisms in the form of minimum standards for labour and environmental protection, as well as facilitating factors and incentives in the form of subsidies to support the introduction of green technologies. The two mechanisms are linked through the possibility of redistributing fines for violating labour and environmental standards to finance subsidies for green innovations. A key finding of the simulations is that sanctions are only effective in combination with innovation subsidies, with the best outcomes involving substantial financial transfers from the Global North to the South.

The final contribution to this collection is about "Digitisation and the Evolution of Money as a Social Technology of Account". Therein Peneder (2021) explores how the social institution of money co-evolves with technology. He emphasises the fact that digital cryptocurrencies were not only initiated but also introduced by computer scientists and took economists by surprise. As a consequence, economists must rethink their basic phenomenology of money. Current developments have major implications for economic policy. First, the diversity of different crypto-coins has proven the technical feasibility of competing private currencies. Second, however, it is doubtful that intense competition will persist in the long run. It is to be feared that the large digital platforms will extend their 
current dominance in the versatile virtual markets to digital payments and money. After the current era of intense creative experimentation with private cryptocurrencies, policymakers face the challenge of preserving public sovereignty over the common unit of account through central bank digital currencies (CBDCs). Their specific configuration and characteristics ultimately depend on a variety of design options and political choices, that will shape the economic system's ability to evolve in a socially desirable way.

Although the individual articles in this issue can each only highlight very specific aspects of a problem, in their entirety they impressively demonstrate the relevance and urgency of developing a genuinely evolutionary perspective on economic policy. We therefore want to conclude this editorial introduction by thanking all the authors most sincerely for their contributions.

\section{Declarations}

Conflict of interests The authors declare to have no conflict of interest. Also no funds, grants, or other support was received.

\section{References}

Cantner U, Pyka A (2001) Classifying technology policy from an evolutionary perspective. Res Policy 30(5):759-775

Dopfer K, Foster J, Potts J (2004) Micro-Meso-Macro. J Evol Econ 14(2):263-279

Gerdes L, Rengs B, Scholz-Wäckerle M (2022) Labor and environment in global value chains: an evolutionary policy study with a three-sector and two-region agent-based macroeconomic mode J Evol Econ. https://doi.org/10.1007/s00191-021-00750-7

Gräbner C, Hornykewycz A (2021) Capability accumulation and product innovation: an agent-based perspective. J Evol Econ. https://doi.org/10.1007/s00191-021-00732-9

Heinrich T, Yang J, Dai S (2021) Levels of structural change: an analysis of China's development push 1998-2014. J Evol Econ. https://doi.org/10.1007/s00191-021-00740-9

Lehmann-Waffenschmidt M, Peneder M (eds) (2022) Evolutorische Ökonomik. Konzepte, Wegbereiter und Anwendungsfelder, Berlin, Springer

Metcalfe SJ (1998) Evolutionary economics and creative destruction. The Graz Schumpeter Lectures, Routledge, London

Nelson RR (2009) Building effective 'innovation systems' versus dealing with 'market failures' as ways of thinking about technology policy. In: Foray D (ed) The new economics of technology policy. Edward Elgar, Cheltenham UK, pp 7-16

Peneder M (2017) Competitiveness and industrial policy: from rationalities of failure towards the ability to evolve. Camb J Econ 41:829-858

Peneder M (2021) Digitization and the Evolution of Money as a Social Technology of Account. J Evol Econ. https://doi.org/10.1007/s00191-021-00729-4

Schmiel U, Sander H (2021) What are markets? Selected market theories under genuine uncertainty compared. J Evol Econ. https://doi.org/10.1007/s00191-021-00728-5

Witt U (2022) Forschungsansätze in der Evolutorischen Ökonomik - ein Überblick. In: LehmannWaffenschmidt M, Peneder M (eds) Evolutorische Ökonomik. Konzepte, Wegbereiter und Anwendungsfelder, Berlin, Springer

Publisher's note Springer Nature remains neutral with regard to jurisdictional claims in published maps and institutional affiliations. 